\title{
SubJeTIVIDAde E SAMBA: \\ NA RODA COM PAULINHO DA VIOLA ${ }^{\star}$
}

Tânia Maia Barcelos $\star \star$

\begin{abstract}
Resumo
A partir do documentário Paulinho da Viola: meu tempo é hoje, busco problematizar a política hegemonica do tempo presente que tem orientado a subjetividade no contexto do capitalismo cultural. No documentário, chamame a atenção, o modo como o compositor trata o tempo e coloca em xeque as formas predominantes de experimentá-lo - capturado num passado saudoso e mal vivido ou num presente cínico, congelado e indiferente aos desassossegos do corpo. O filme leva-me a vislumbrar linhas de resistência e invenção da subjetividade; resistência à política hegemônica do tempo presente e invenção de novas temporalidades, potências vitais em contextos de extrema aceleração e sutis controles da vida.
\end{abstract}

Palavras-chave: subjetividade; tempo; samba; contemporaneidade.

\section{SUBJECTIVITY AND SAMBA: IN THE CIRCLE WITH PAULiNho DA ViOLA}

\begin{abstract}
From the documentary Paulinho da Viola: meu tempo é hoje (Paulinho da Viola: my time is today), I aim at problematizing the hegemonic politics at the present time which has oriented the subjectivity in the cultural capitalism context. In the documentary, what draws my attention is the way the composer treats time and puts in jeopardy the predominant forms of experimenting it-captured in a longing past and badly lived or in a cynical present, frozen and indifferent to the body's restlessness. The movie leads me to glimpse the resistance lines and the subjectivity invention; resistance to the hegemonic politics of the present time and invention of new temporalities, vital potencies in extreme acceleration contexts and subtle life controls.
\end{abstract}

Keywords: subjectivity; time; samba; contemporaneity.

\footnotetext{
^Este texto é parte da tese de doutorado: "Re-quebros da subjetividade e o poder transformador do samba", concluída em 2006, no Programa de Estudos Pós-graduados em Psicologia Clínica da Pontifícia Universidade Católica de São Paulo, sob orientação da Professora Dra Suely B. Rolnik.

$\star \star$ Professora do Curso de Psicologia da UFG/ Campus Catalão. Doutora em Psicologia pela Pontifícia Universidade Católica de São Paulo. Endereço: Rua Oscar Gomes Moreira, 386. Bairro Tubalina. Uberlândia - MG. CEP: 38412.044

E-mail: taniab@triang.com.br
} 


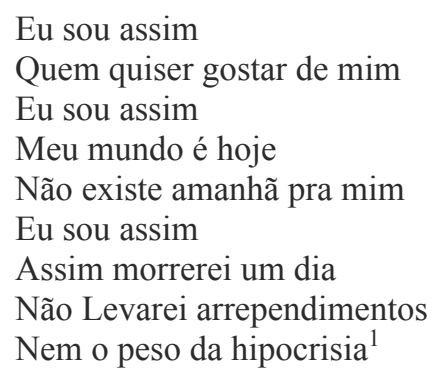

Ele chega assim: alegre, calmo, sorrateiro, sorrindo e cumprimentando seus amigos e admiradores. Aproxima-se da roda como qualquer outro e, aos poucos, ocupa o lugar especial que todos lhe reservam: de homenageado, da festa, regada com muita comida e samba de boa qualidade. Bastante à vontade, ele canta e toca com seus parceiros, que lhe ajudam a sustentar um clima de aconchego e alegria. Esta é uma das belas cenas que compõem o filme: Paulinho da Viola: meu tempo é hoje. ${ }^{2}$

Delicado e sutil, o documentário mostra a rotina discreta, os hábitos, os amigos, os amores, os encontros musicais e as reflexões deste grande compositor, que afirma sem embaraços: "eu não vivo no passado, o passado vive em mim". Comentado por vários críticos e apreciadores, o filme aborda uma questão essencial que atinge a subjetividade ${ }^{3}$ contemporânea: as formas de se viver o tempo.

Não é por acaso que o psicanalista Contardo Calligaris (2003) atribuiu ao compositor o título de "terapeuta da nossa relação doentia com o tempo". Relação em que o presente é vivido como ponto culminante de uma história de sucesso, e o instante atual é apenas uma etapa em função do que vem depois. Esta forma de lidar com o tempo, produzida na modernidade, apaga o presente e faz a subjetividade viver em trânsito - entre um passado, objeto de saudade e currículo de potencialidades futuras, e o anseio por dias melhores. Sem dignidade própria, o presente "é a fração de segundo em que o atleta de salto triplo pisa na areia para impulsionar-se e pular mais longe" (CALLIGARIS, 2003).

Segundo o psicanalista, há um distanciamento entre a experiência moderna do tempo e a proposta de Paulinho da Viola, que afirma o presente, sem lamentar o passado ou alimentar sonhos futuros. Essa relação com o tempo é vivida na música e em diversas atividades que o compositor executa no dia a dia, tais como restaurar carros velhos e reparar relógios. Ambas sustentam um tempo sem pressa e sem preocupação com resultados finais. Os carros, por exemplo, são restaurados durante anos, não para serem utilizados, mas como meio de exercitar uma capacidade extraordinária de usufruir do presente. Um presente que mostra dignidade, valor e grandeza da vida na hora em que ela acontece. Esses são os elementos que o psicanalista Contardo Calligaris considera terapêuticos da nossa relação doente com o tempo, muitas vezes, incapaz de viver o presente.

Embora essa leitura do filme aponte algumas pistas importantes para a compreensão das formas de se viver o tempo na contemporaneidade, ela não problematiza a política do presente em jogo na postura de Paulinho da Viola. Talvez o 
aspecto mais charmoso do filme esteja, exatamente, na sutileza com que o compositor nos convida a inventar uma política do presente. Política que atualiza o passado como força mobilizadora de sua estética musical, atravessada pelas "coisas do mundo" e aberta a novas experimentações. O compositor faz questão de destacar como foram decisivos na sua formação os encontros com a arte de Pixinguinha, Wilson Batista, Cartola, Jacob do Bandolim, Noel Rosa e tantos outros que ele respeita e admira, porque o contagiam com "coisas muito vivas", mesmo que sejam de 70 anos atrás. "O que me sensibiliza é o que está vivo em mim".

A sua política do presente não exclui o novo, nem adere à estética do novo pelo novo (COUTINHO, 2002), estratégia habitual em nossa cultura, muitas vezes, deslumbrada com tudo que se apresente como tal. Paulinho da Viola não cultua o passado, nem preserva uma cultura autêntica, pura e marginal. Sua obra, como afirma Coutinho, (2002) marca uma posição de compromisso com a reconstrução da memória coletiva de um grupo marginalizado da sociedade. Aceita a irrupção do novo, mas recusa o culto à ruptura. Não há em sua obra uma preocupação de preservar um conteúdo morto, nem de embarcar, alegremente, na indústria do entretenimento. Como diz o compositor, "não tenho preocupação em estar na moda, nem nunca tive preocupação de ser defensor do samba tradicional."4

Se insiste em dizer que seu mundo é hoje, também sustenta que seu mundo é o do velho marinheiro que leva o barco devagar. Ou seja, sem mania de passado e sem querer ficar do lado de quem não quer navegar. ${ }^{5}$

\author{
Quem me navega é o mar \\ É ele que me carrega \\ Como nem fosse levar \\ E quanto mais remo mais rezo \\ Pra nunca mais se acabar \\ Esta viagem que faz \\ O mar em torno do mar \\ Meu velho um dia falou \\ Com seu jeito de avisar: \\ - Olha, o mar não tem cabelos \\ Que a gente possa agarrar ${ }^{6}$
}

É assim que Paulinho da Viola navega: com a impressão de que está "lá longe", como se não aceitasse o tempo dentro do qual está vivendo e andasse mais devagar. ${ }^{7}$ Seu presente é denso, espesso e acolhedor da variação rítmica da vida, na contramão das propostas mercadológicas do tempo, que tentam nos convencer de que é preciso viver intensamente o presente, direcionar o olhar para o futuro e impedir que o passado atrapalhe nossos planos. ${ }^{8}$ Aliás, tem sido mal visto não se desprender do passado, pois isto dificulta a consolidação da política de flexibilidade do capitalismo contemporâneo, que leva as pessoas a aderirem apressadamente aos novos estilos de vida produzidos pelo mercado e supostamente acessíveis a qualquer um. 
Não importa se os corpos não aguentam a sensação de descompasso com o ritmo alucinante ou se não conseguem digerir tudo o que acontece "a tempo e a hora". O que importa é não perder o bonde que os mantêm antenados com o mundo globalizado e virtual, postura que depende de ignorar o corpo intensivo - que apreende o mundo como sensação e estranhamento e não como representação - e construir territórios a partir de imagens prêt-à-porter, digeridas acriticamente. "O que nos guia nesta empreitada, em nossa flexibilidade pós-fordista, é a identificação quase hipnótica com as imagens de mundo veiculadas pela publicidade e pela cultura de massa" (ROLNIK, 2006, online).

Alguns autores, como Pelbart (2000), chamam o regime temporal que vem presidindo nossas vidas de "ditadura do presente" ou "congelamento cínico do presente", sem densidade e sem espessura. Nesse regime, que altera não somente nossa relação com o passado e com o futuro, mas, também, nossa vivência do instante e nossa fantasia de eternidade, a subjetividade quase não saboreia as sutilezas e a diversidade dos ritmos do tempo; é levada a acreditar num presente livre de pesos e desassossegos. Como afirma o autor,

Já não navegamos num rio do tempo, que vai de uma origem a um fim, mas fluímos num redemoinho turbulento, indeterminado, caótico. A direção do tempo se dilui a olhos vistos. Também a espessura do tempo se evapora, nem mais parecemos habitar o tempo, e sim a velocidade instantânea, ou a fosforescência das imagens, ou os bits de informação. Qualquer reflexão sobre a chamada pósmodernidade gira em torno dessa mutação, que alguns apresentam de maneira mais apocalíptica ou saudosista, outros com voluptuosa euforia, outros ainda com cinismo e sarcasmo (PELBART, 2000, p.188).

Para Pelbart (2000) o que está em jogo é outro regime temporal. Não se trata de lamuriar a perda de antigas formas do tempo, mas ir além desta nostalgia. Afinal, o que se perdeu foi um determinado tempo, e isto não é lamuriento, nem jubiloso, mas provocativo, pois nos convida a inventar outras maneiras de se lidar com ele.

Paulinho da Viola aceita o convite e coloca em xeque nossa relação hegemônica com o tempo, muitas vezes apegada a um passado saudoso e mal vivido, e, outras vezes, capturada num presente cínico, congelado e indiferente aos desassossegos do corpo e da subjetividade. É isso que o compositor nos força a pensar: na possibilidade de resistir a essa política e inventar outras temporalidades. Se há algum efeito terapêutico nessa postura, não se trata apenas de afirmar o presente, mesmo porque isto pode ser confundido com certas políticas mercadológicas do tempo, que fazem apologias ao novo, mas não o acolhem, efetivamente.

Como bem lembra Rolnik (1997), a abertura para o novo não envolve, necessariamente, abertura para o estranho, nem tolerância ao desassossego e, menos ainda, disposição para criar figuras singulares orientadas pela cartografia dos 
ventos revoltos da atualidade. Muitas vezes, a abertura para o novo é vivida como conquista de flexibilidade para se adaptar às novas roupagens do sistema vigente com mais desenvoltura e criatividade.

Isso não é suficiente para problematizarmos as políticas temporais que têm orientado nossa subjetividade. Mais que isso, é necessário desconfiar do novo como algo a ser consumido ou incorporado, compulsivamente, visando a nos proteger de inúmeras formas de exclusão, que hoje abrangem até o fato de não se conectar à internet, não estar antenado aos últimos lançamentos da moda, da tecnologia ou aos novos paradigmas mais bem vistos socialmente. É fundamental estar à escuta dos estranhos signos do mundo que afetam nossos corpos e nos obrigam a criar outros modos de existência.

\title{
UM SAMBA SOBRE O INFINITO
}

\author{
Silêncio por favor \\ Enquanto esqueço um pouco \\ A dor no peito \\ Não digam nada sobre meus defeitos \\ Eu não agüento mais quem me deixou assim \\ Hoje eu quero apenas \\ Uma pausa de mil compassos ${ }^{9}$
}

Contrariando a lógica do presente, que anula a densidade do tempo e não tolera qualquer tipo de espera, Paulinho da Viola insiste: "hoje eu quero apenas uma pausa de mil compassos"; um tempo de duração esticada, de elaboração, de esquecimento e de criação de infinitos sambas e formas de amar e viver. ${ }^{10}$

\author{
Se for preciso eu repito \\ Porque hoje eu vou fazer \\ Ao meu jeito \\ Eu vou fazer \\ Um samba sobre o infinito ${ }^{11}$
}

Em tempos como os nossos, extremamente velozes e quase destituídos de pausas, sejam formais ou intensivas, Paulinho da Viola sugere entretempos de espera e de incertezas abertos aos acasos e às improvisações. Entretempos que se movem por estranhamento e embaralham a apreensão do mundo, do outro e de si mesmo como representação construída previamente. Tais pausas são experimentadas não como paradas formais ou interrupções temporárias de ação ou movimento. Esta é a definição do termo pausa no dicionário ou o modo como a vivemos cotidianamente.

Nos entretempos estéticos de Paulinho da Viola, a subjetividade perde a nitidez de seus contornos e se expõe a certos nomadismos e acasos. Como diz o compositor, "o acaso não tem pressa", ${ }^{12}$ pois não é um incidente a ser afugentado, mas um elemento essencial nos processos de criação, que ocorrem na relação com o tempo. O acaso, o inesperado, possibilita o devir e a emergência de novas formas de vida, que não duram eternamente. O tempo se encarrega de destruí- 
las e de construir outras infinitamente. "O que vem até nós, o inesperado que, de algum modo, se espera que venha, surge como absolutamente necessário: se o queremos, se o afirmamos com toda nossa vontade, ele nos traz o presente e impulsiona à ação, a uma ação criadora" (DIAS, 2004).

Nos entretempos ou intervalos intensivos, os afetos são experimentados de outras maneiras. A solidão - lava que cobre tudo - "não é demais"13 e pode ser vivida sem pesos e sem dramas, "até saber se o coração já se refez". ${ }^{14} \mathrm{O}$ esquecimento é fundamental. Afinal,

\author{
O que pode fazer \\ Um coração machucado \\ Senão cair no chorinho \\ Bater devagarinho pra não ser notado \\ E depois de ter chorado \\ Retirar de mansinho \\ De todo amor o espinho \\ Profundamente deixado \\ O que pode fazer \\ Um coração imprudente \\ Se não fugir um pouquinho \\ De seu bater descuidado \\ E depois de cair no chorinho \\ Sofrer de novo o espinho \\ Deixar doer novamente. ${ }^{15}$
}

$\mathrm{O}$ esquecimento permite anular o efeito das marcas envenenadoras, que produzem ruminações improdutivas e paralisam o desejo como possibilidade de expansão da vida. É preciso

Esquecer para não morrer da memória! Esquecer para não deixar que o torturador, o violento, o déspota riam ao constatar que a vítima de ontem, hoje, livre das amarras e dos golpes sádicos, continue sendo o refém infeliz e ressentido, $\mathrm{o}$ adorador de seu algoz, atado à impossibilidade de esquecer o esquecimento, que fez da memória passiva, sua própria prisão [...] e seu túmulo! (LINS, 2000, p.51).

Se o ressentido caracteriza-se por uma prodigiosa memória e pelo poder de conservar, o criador se define pela faculdade de esquecer e pelo poder de criar. O ressentido conserva a vida, mas impede que ela seja reinventada. Sua memória excessiva é venenosa, e seu processo de digestão é lento, pesado e difícil de ser metabolizado. É como se ele nunca estivesse pronto para viver o presente e o novo. As lembranças lhe ulceram a alma e alimentam suas feridas. Por isso, ele não exorciza os demônios que voltam, constantemente, a encarnar novas formas de existência (DIAS, 1994). ${ }^{16}$ 
O criador, ao contrário, sabe esquecer e não leva muito a sério os contratempos e malfeitos. Se ele esquece, se recorda, pois é só assimilando o passado que se torna possível destruir certas formas de vida e construir outras. Para impedir a fixação das marcas envenenadoras da memória, o criador torna-se inapto tanto para o perdão como para a culpa. Ele esquece não para perdoar, mas para sustentar uma outra memória e continuar desejando a vida.

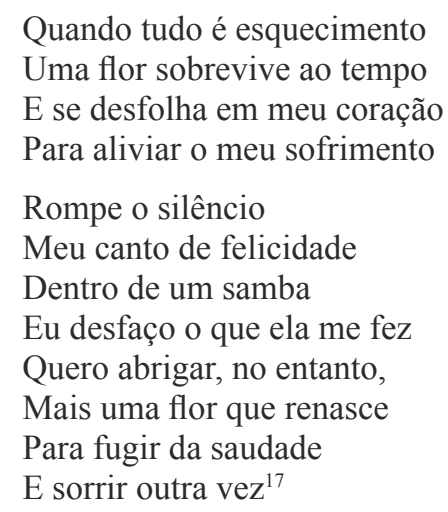

Os entretempos, que Paulinho da Viola sugere em suas composições, são generosos e abertos aos deslocamentos dos ritmos e das políticas temporais hegemônicos, pouco tolerantes a qualquer tipo de espera e esquecimento como possibilidades de potencialização dos corpos e da subjetividade. Sabemos na pele o quanto tem sido difícil suportar as esperas nos diversos espaços em que transitamos - bancos, supermercados, hospitais, pontos de ônibus, cinemas, bares, restaurantes, aeroportos etc. Mais insuportáveis ainda têm sido os intervalos existenciais, especialmente, aqueles dedicados à construção de novas formas de vida.

Se, até alguns anos atrás, a subjetividade moderna resistia, duramente, a se desgrudar das referências que lhe davam estabilidade, com receio de perder seus contornos e suas formas, hoje é convocada a isto, incessantemente. Sem tréguas e sem resistência, ela embarca nos processos de invenção predominantes que exigem: mudar sempre, tendo em vista a adaptação contínua às novas formas de vida produzidas em série e de modo acelerado. A demanda interminável de trabalho e atividades extras, inclusive em casa e nos momentos de lazer, dificulta ainda mais a criação de espaços de problematização das políticas do tempo, que, geralmente, nos deixam com medo de sermos engolidos por ele.

Chamo os entretempos estéticos de Paulinho da Viola de "gordos intervalos intensivos", sem medidas, amplos e generosos. Eles não se não confundem com o tempo do relógio, nem com o tempo do computador. Destoam dos tempos e ritmos dominantes que orientam nossas vidas, acelerando-as e lentificando-as de forma programável. Os "gordos intervalos intensivos", presentes nos processos de criação, pedem paciência para que o tempo e a forma brotem a partir do informe. "O desafio é propiciar as condições para um tempo não controlável, não programável, que possa trazer o acontecimento que nossas tecnologias insistem em neutralizar" (PELBART, 1993, p. 36). 
Sustentar esse tempo não é fácil, pois, como argumenta Pelbart (1993), a subjetividade hegemônica moderna é amante das formas, dos projetos e do futuro já embutido no presente. Mas é necessário afirmá-lo, se quisermos experimentar outras maneiras de viver o tempo e nos contrapor à violência da cronopolítica hegemônica, ${ }^{18}$ que nos leva a confundir velocidade com inércia e instantaneidade com imobilidade.

Afirmando esse tempo generoso, de "instantes intensivos gordos", podemos vislumbrar linhas de resistência e de invenção de novas temporalidades. Claro que a afirmação desse tempo vem acompanhada de medo. Sim, pois, muitas vezes, temos receios de experimentar pausas e intervalos até mesmo como paradas formais de alívio do corpo, que também são indispensáveis à nossa existência. Com medo ou não, a escuta deste apelo vital do corpo é uma possibilidade de aprendizado, difícil de acontecer sem alguns aliados que nos ajudem a enfrentá-lo efetivamente.

\title{
NuM SAMBA CURTO, NINGUÉM PODE EXPLICAR A VIDA...
}

\author{
Ela não é uma equação \\ Não tem que ser resolvida \\ A vida, portanto, meu caro \\ Não tem solução ${ }^{19}$
}

Fazer alianças com as possibilidades temporais que perpassam a postura de Paulinho da Viola - seja nas composições ou nos modos de vida singulares que busca sustentar - é apostar em outras experimentações do tempo. Experimentações que nos levam a mergulhar no estranho aprendizado da diferenciação rítmica da vida, decorrente de dois movimentos imprescindíveis: a apreensão do mundo como matéria-forma e a apreensão como matéria-força. ${ }^{20}$ Esse aprendizado, que ocorre entre dois meios - as formas existentes e o informe - , é essencialmente rítmico e garante não somente o desmanche de antigos territórios, mas também a constituição de novos mundos, finitos e provisórios. Aprendemos quando nossa sensibilidade é posta a serviço dos estranhamentos experimentados nos encontros.

$\mathrm{Na}$ roda com o cantor e compositor Paulinho da Viola, os estranhamentos deslocam as formas dominantes de se viver o tempo e criam outras modalidades de vida. Isso é fundamental em contextos nos quais a vida mesma tornou-se um capital, senão 'o' capital por excelência, como afirma Pelbart (2003, p. 13):

Nunca o capital penetrou tão fundo e tão longe no corpo e na alma das pessoas, nos seus genes e na sua inteligência, no seu psiquismo e no seu imaginário, no núcleo de sua "vitalidade". Ao mesmo tempo, tal "vitalidade" tornou-se a fonte primordial de valor no capitalismo contemporâneo: a produção imaterial seria impensável sem a força de invenção disseminada por toda parte. Reservatório inesgotável de gens e de idéias, de invenção e de recomposições, a vida é, 
afinal, um capital comum. Ao menos em tese pertencente a todo mundo, é a vida que serve de ponto de apoio último para novas lutas e reivindicações coletivas.

Nos contextos de inúmeras formas de exercício de poder sobre a vida, o sambista aposta na sua potência política, lembrando de que ela não é uma equação passível de ser solucionada e "toda hora rola uma história que é preciso estar atento/ a todo instante rola um movimento que muda os rumos do vento". ${ }^{21}$ Além de apostar na criação de outras modalidades de vida, o sambista chama a atenção para a necessidade de ficarmos alertas e nos convida ao aprendizado: "quem sabe remar não estranha".22

O movimento rítmico e incerto da vida oferece elementos para a produção estética de Paulinho da Viola, que afeta os corpos em diversos tipos de encontros sonoros e musicais. No processo de criação, o artista aprende a dar melodia à verdade do que viu, viveu, sentiu e a transfigurar em arte a dor dos afetos (DIAS, 2004). Cantada, essa dor adquire uma forma sonora e conquista outras durações. Torna-se transitória e possibilita a experiência lúdica da alegria musical. É que o artista cria e resiste quando libera a vida das prisões culturais. "O artista é quem libera uma vida potente, uma vida mais do que pessoal. Não é a vida dele". ${ }^{23}$

Sem dúvida, a estética da vida que Paulinho da Viola sugere abre algumas frestas de alegria, em tempos tímidos e frágeis de resistência. Esta estética faz com que a percepção predominante da vida - centrada em representações que a concebem como "equação" a ser resolvida e focada na busca de um ideal de estabilidade e completude - seja problematizada. Tal concepção, bastante presente na modernidade, ainda prevalece no mundo contemporâneo, apesar das novas versões do regime capitalista, que investe, fortemente, na flexibilidade dos comportamentos e da vida. Essas versões continuam intolerantes à inevitável dimensão trágica da vida, que não promete final feliz, nem fórmulas mágicas, por mais que tenhamos jogo de cintura e criatividade para acompanhá-las; por mais que acreditemos nas formas emergentes de ilusão de estabilidade.

Como afirma Deleuze (1995, online) $:^{24}$

A vida está em toda parte, em todos os momentos que tal ou qual sujeito vivo atravessa e que tais objetos vividos medem: vida imanente que transporta os acontecimentos ou singularidades que não fazem mais do que se atualizar nos sujeitos e nos objetos. Essa vida indefinida não tem, ela própria, momentos, por mais próximos que sejam uns dos outros, mas apenas entre-tempos, entre-momento.

Nessa perspectiva, a vida é impessoal, informe, imprevisível, criadora e sem imagem. Ela se caracteriza como uma multiplicidade de planos de existência - aquém da organização das formas constituídas - e é atravessada por linhas de desterritorialização que a arrastam para limiares inéditos. 
Sem dúvida, essa concepção da vida tem ressonâncias com a estética de Paulinho da Viola, que busca experimentá-la como multiplicidade aberta "às coisas do mundo" e às formas de existência ainda por vir. Na contramão dos cenários político-culturais que depreciam a vida e a reduzem "a uma vida besta em escala planetária" (PELBART, 2006), o compositor aposta em outra direção. Por meio de sons, melodias, ritmos, acordes, palavras, ele a afirma com tudo que ela comporta e vislumbra outros afetos, tempos, pausas e esperas. Finitas formas de vida. Infinitos sambas.

\author{
Mais não se pode dizer \\ Nem eu, nem ninguém \\ Você é quem deve colher \\ Depois de semear também \\ Você é quem pode rasgar o caminho \\ E fechar a ferida \\ E achar o seu justo momento \\ A razão de tudo aquilo que chamamos vida. ${ }^{25}$
}

\title{
Notas
}

${ }^{1}$ Letra de Wilson Batista e José Batista: Meu mundo é hoje (eu sou assim). Cd $A$ dança da solidão - Paulinho da Viola. São Paulo: EMI Music LTDA, 1996.

${ }^{2} \mathrm{O}$ filme, dirigido por Izabel Jaguaribe, com roteiro do jornalista Zuenir Ventura, foi produzido por

Videolar, Indústria Brasileira, sob licença de Videofilmes Produções Artísticas LTDA. 2003.

${ }^{3}$ Subjetividade, aqui, não é concebida como algo interno, centrado no indivíduo. Refere-se aos modos de existência construídos historicamente e vividos por indivíduos em suas existências particulares. São provisórios e abertos às linhas de fuga, as quais possibilitam novas configurações existenciais.

${ }^{4}$ Depoimento do compositor ao Correio da Manhã, em 24/01/1970 (In: COUTINHO, 2002: 111).

${ }^{5}$ Paulinho da Viola. Argumento. Cd Bebadachama. São Paulo: BMG, 1997.

${ }^{6}$ Paulinho da Viola e Hermínio Bello de Carvalho. Timoneiro. Cd Bêbadachama. São Paulo: BMG, 1997.

${ }^{7}$ Conforme depoimento a Eduardo G. Coutinho (Op. cit. p. 148), em 13 de Janeiro de 1999.

${ }^{8}$ Tal postura está muito presente nas literaturas de auto-ajuda consumidas por uma grande parcela da população nas últimas décadas.

${ }^{9}$ Paulinho da Viola. Para ver as meninas. Cd Paulinho da Viola. São Paulo: EMI-Odeon, 1971.

${ }^{10}$ Paulinho da Viola e Elton Medeiros. Vida. Cd Paulinho da Viola. São Paulo: EMI-Odeon, 1975.

${ }^{11}$ Paulinho da Viola. Para ver as meninas. Cd Paulinho da Viola. São Paulo: EMI-Odeon, 1971.

${ }^{12}$ Título de uma composição de Paulinho da Viola e Capinan. Cd Paulinho da Viola. São Paulo: EMI-Odeon, 1971b.

${ }^{13}$ Paulinho da Viola. Depois de tanto amor. Cd Samba na madrugada - Paulinho da Viola e Elton Medeiros. São Paulo: RGE, 1968.

${ }^{14}$ Idem.

${ }^{15}$ Paulinho da Viola e Capinam. Coração imprudente. Cd $A$ dança da solidão. São Paulo: EMIOdeon, 1972.

${ }^{16}$ Ver também Dias (2004, op. cit) e FERRAZ, M.C. Nove variações sobre temas nietzschianos. Rio de Janeiro: Relume Dumará, 2002.

${ }^{17}$ Paulinho da Viola e Elton Medeiros. Pra fugir da saudade. Cd Aurora da paz. Rio de Janeiro: Rob Digital, 2001.

${ }^{18}$ Conforme Pelbart (1993), nesta cronopolítica há "um achatamento temporal que proporciona um presente eterno, sem história para trás nem para frente, sem passado nem futuro" (pg.34). Tal política do tempo - hegemônica nas últimas décadas, em função do avanço tecnológico/científico e das novas exigências do capitalismo cultural - vem nos violentando, significativamente. 
${ }^{19}$ Paulinho da Viola e Ferreira Gullar. Solução de vida (molejo dialético). Cd Bêbadachama. São Paulo: BMG, 1997.

${ }^{20}$ Conferir os trabalhos de Suely Rolnik, especialmente, o texto "Geopolítica da cafetinagem" (op. cit) disponível no site do Núcleo de Estudos da Subjetividade/PUC-SP.

${ }^{21}$ Paulinho da Viola. Rumo dos ventos. Cd A toda hora rola uma estória. WEA, 1982.

${ }^{22}$ Idem.

${ }^{23}$ DELEUZE, G. O abecedário de Gilles Deleuze. Disponível em: http://www.dossie deleuze. blogger.com.br. Acesso em 16 de Julho de 2008.

${ }^{24}$ Ver, também, o conceito de vida em: ZOURABICHVILI. F. O vocabulário de Deleuze. Tradução André Telles. Rio de Janeiro: Relume Dumará, 2004.

${ }^{25}$ Paulinho da Viola e Elton Medeiros. Vida. Cd Paulinho da Viola. São Paulo: EMI-Odeon, 1975.

\section{REFERÊNCIAS}

CALLigARIS, C. Paulinho da Viola e nosso uso do tempo. Folha de S. Paulo, Agosto de 2003.

COUTINHO, E. G. Velhas histórias, memórias futuras: o sentido da tradição na obra de Paulinho da Viola. Rio de Janeiro: EdUERJ, 2002.

DELEUZE, G. A imanência: uma vida (1995). Tradução de Tomaz Tadeu da Silva. Disponível em: http://www.dossie_deleuze.blogger.com.br. Acesso em 16 de Julho de 2008.

. O abecedário de Gilles Deleuze. Disponível em: http://www.dossie deleuze.blogger.com.br. Acesso em 16 de Julho de 2008.

DIAS, R. As paixões tristes: Lupicínio e a dor-de-cotovelo. Rio de Janeiro: Leviatã Publicações, 1994.

. A vida como vontade criadora: por uma visão trágica da existência. In: FONSECA, T.; ENGELMAN, S. (Org.). Corpo, arte e clínica. Porto Alegre: UFRGS, 2004. p. 131-146.

FERRAZ, M.C. Nove variações sobre temas nietzschianos. Rio de Janeiro: Relume Dumará, 2002.

LINS, D. Esquecer não é crime. In: LINS, D; COSTA, S. G.; VERAS (Org.). Nietzsche e Deleuze: Intensidade e Paixão. Rio de Janeiro: Relume Dumará, 2000. p. 45-62.

PAULINHO da Viola - meu tempo é hoje. Direção: Izabel Jaguaribe. Produção: Maurício Andrade Ramos. Rio de Janeiro: Videofilmes, 2003. 1 DVD.

PELBART, P. P. A nau do tempo rei: 7 ensaios sobre o tempo da loucura. Rio de Janeiro: Imago, 1993. 
PELBART, P. P. A vertigem por um fio: Políticas da subjetividade contemporânea. São Paulo: Iluminuras, 2000.

. Vida Capital: ensaios de biopolítica. São Paulo: Iluminuras, 2003.

. Vida nua, vida besta, uma vida. 2006. Disponível em: http://p.php.uol. com.br/tropico/html/textos. Acesso em 16 de Julho de 2008.

ROLNIK, S. Uma insólita viagem à subjetividade: fronteiras com a ética e a cultura. In: LINS, D. (Org.). Cultura e subjetividade: saberes nômades. Campinas, SP: Papirus, 1997. p. 25-34.

Geopolítica da cafetinagem. 2006. Disponível em: http://www.pucsp. br/nucleodesubjetividade. Acesso em 16 de Julho de 2008.

ZOURABICHVILI. F. O vocabulário de Deleuze. Tradução André Telles. Rio de Janeiro: Relume Dumará, 2004.

Recebido em: fevereiro de 2009

Aceito em: abril de 2009 